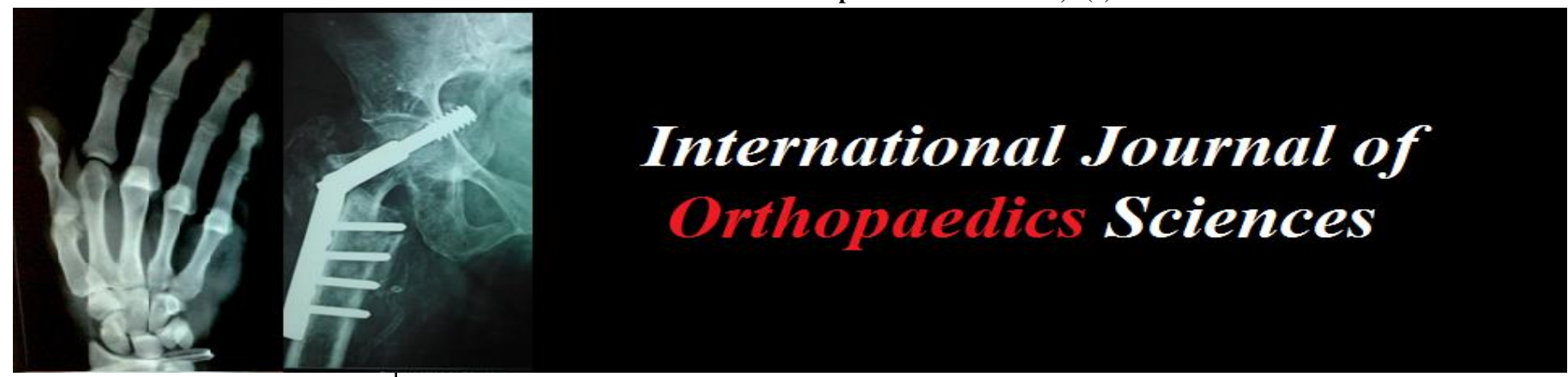

ISSN: $2395-1958$

IJOS 2019; 5(2): 684-687

(C) 2019 IJOS

www.orthopaper.com

Received: 09-02-2019

Accepted: 13-03-2019

Dr. Shrinivas Prakash MBBS, MS (Ortho)

Professor Hardikar Hospital

Pune, Maharashtra, India

Dr. Varun Rao

MBBS, DNB orthopedic surgery

Spine Fellow Hardikar Hospital,

Pune, Maharashtra, India

Dr. Sharad Hardikar

MB, FRCS, Head of department

Hardikar Hospital, Pune,

Maharashtra, India

Dr. Saurabh Pagdal

MBBS, DNB orthopedic surgery

Senior Resident, Hardikar

Hospital, Pune, Maharashtra,

India
Correspondence

Dr. Saurabh Pagdal

MBBS, DNB orthopedic surgery

Senior Resident, Hardikar

Hospital, Pune, Maharashtra,

India

\section{External fixators in management of high energy distal third tibia fractures}

\author{
Dr. Shrinivas Prakash, Dr. Varun Rao, Dr. Sharad Hardikar and Dr. \\ Saurabh Pagdal
}

DOI: https://doi.org/10.22271/ortho.2019.v5.i2j.74

\section{Abstract}

Background: Outcomes of management of high energy distal third tibial fractures are not satisfactory and associated with complications. So use of external fixator is increased in recent years for distal third tibia fractures. We intend to study the utility of external fixators in high energy distal third tibial fractures.

Materials and Methods: This is retrospective observational study included 38 patients who underwent close reduction and external fixation with Augmented Wagners external fixator or Aesculap external fixator(unilateral) or Hybrid external fixator for lower third tibial fractures in between 2009 and 2015.

Results: The Olerud C and Molander H ankle score was excellent in $44.73 \%(\mathrm{n}=17)$, good in $31.57 \%$ $(\mathrm{n}=12)$, fair in $15.78 \%(\mathrm{n}=6)$ and poor in $7.89 \%(\mathrm{n}=3)$. The ankle range of movement was near normal in $94.73 \%$ cases except in 2 patients where stiffness was encountered. The average duration of union was 6 months and $89 \%(n=34)$ of fractures united within 7 months. $P$ value $<0.05(0.066)$ was not considered significant.

Conclusion: External Fixators with or without limited percutaneous internal fixation is a reliable method for stabilization of high energy (Tscherne 2 and 3, compound) lower third tibial fractures. It's a good alternative to other methods of fixation in lower third tibia fracture.

Keywords: distal tibia; pilon fracture; external fixator

\section{Introduction}

Distal third tibia fractures are divided into low energy and high energy fractures. High energy fractures occur in fall from height, motor vehicle accident, Workplace accidents ${ }^{[1-3]}$.

Distal third tibia has thin soft tissue cover ${ }^{[3]}$. so high energy distal tibia fractures are associated with soft tissue damage, severe edema, open wound, contamination, bony devascularization and also articular comminution and metaphyseal impaction [3-7] That's why surgical management of high energy distal tibia fractures is complex and challenging. Outcomes of high energy distal third tibial fractures are not satisfactory and associated with complications ${ }^{[2,8,9]}$ Complication rates are higher with plating in cases of extensive soft tissue damage ${ }^{[3]}$. So use of external fixator are increased in recent years for distal third tibia fractures ${ }^{[2,3]}$

We are currently using three types of external fixators in fractures of lower third tibia. Depending upon type or nature of fracture as per OTA classification ${ }^{[10]}$ the appropriate type of fixator will be applied. Frame of fixators we are using in the study are unilateral. We intend to study the utility of external fixators in high energy distal third tibial fractures.

\section{Materials and Methods}

This is retrospective observational study included 38 patients who underwent close reduction and external fixation with Augmented Wagners external fixator or Aesculap external fixator(unilateral) or Hybrid external fixator for lower third tibial fractures in between 2009 and 2015 .

Inclusion criteria included

1. Patients with closed fractures of distal third tibia with significant soft tissue injury Tscherne ${ }^{[11]}$ type 2 and 3. 
2. Patients with compound fractures of the distal third tibia with all Gustilo-Anderson ${ }^{[12]}$ types i.e. Type 1, 2, 3 .

\section{Exclusion criteria included}

1. Patients with age below 16 years

2. Patients with OTA type42-B3,42-C3,43-B1,43-B2 and 43-B3

\subsection{Operative method}

Pre-operative radiographic evaluation was done with AnteroPosterior and Lateral view X-ray of the ankle joint with full length tibia and fibula. 3D reconstruction CT scan was done if fracture pattern involves intra-articular surface.

After giving spinal anaesthesia patient, the patient was placed on a traction table for providing ligamentotaxis.

\section{Selection of fixator}

Whether to use Augmented Wagners External fixator or Aesculap External Fixator will depend on requirement of post-operative fracture site compression to achieve bone to bone contact. Especially in severe metaphyseal communition, here we would prefer Augmented Wagners External Fixator. In others who would not require any compression post operatively, the Simple external fixator with Aesculap clamps and rod will be used.

\section{For augmented wagners external fixator}

Augmented Wagner's external fixator either long or extra long size is selected according to the length of tibia. The clamps are then appropriately arranged and the fixator is held medially and parallel to tibia. Initially proximal most $4.5 \mathrm{~mm}$ Schanz pin is introduced at right angle to the longitudinal axis of tibia at level of just proximal to tibial tuberosity. Then the distal Schanz pin passed through the anteromedial part of the lower end of tibia which is just proximal to the joint line directing it posterolaterally. The second distal Schanz pin is introduced from posteromedial part directing it anterolaterally. Both these are passed through the Rancho cubes which is fixed to the Ilizarovs quarter ring (mounted on clamp)is attached to the inner tube of the fixator. So this clamp is at right angle to the other 3 clamps. The third and fourth pins are passed through Wagners clamp fixed to the body of inner tube into the distal tibial segment. Sometimes a Schanz pin is introduced through the medial malleolus directing proximally and laterally through Aesculap clamp just attached to stud distal to the Ilizarov quarter. Proximal segment of tibia is held by 4 Schanz pin mounted through the 2 Wagners clamp. The proximal 2 pins are perpendicular to the long axis of tibia while the other two are directed obliquely close to fracture site in the proximal tibial segment. For obtaining anatomical reduction the Schanz pins close to fracture sites are pushed or pulled to bring about medial/lateral bone alignment. For attaining antero posterior alignment $\mathrm{Z}$ bender is used to bend shaft of Schanz pins. All the nuts of clamps and the bolts of Rancho cubes are fastened after checking fracture ends under image intensifier. Gentle compression is given to bring about bone to bone contact in the region of metaphysis.

\section{For aesculap external fixator}

Appropriate length of rod is selected according to length of tibia 5 to 6 clamps are beaded onto the rod and held medially and parallel to tibia. The proximal and distal most Schanz pins are initially introduced at right angle to the tibia. The proximal pin is parallel to the tibial plateau just proximal to tibial tuberosity and distal one is just proximal to the ankle joint. Sometimes if the distal segment is rather short then a Schanz pin is introduced through the medial malleolus. In the proximal segment a Schanz pin is introduced obliquely close to the fracture site. Similarly another Schanz pin is introduced to the distal segment also close to fracture. So a total of 3 to 4 Schanz pins are in each of the proximal and distal tibial segments.

\section{For hybrid external fixators}

While using any of the two fixators where the fracture fragments are not in contact with each other $\mathrm{K}$ wires / screws can be introduced percutaneously to bring fragment close to each other for obtaining good reduction and alignment of the fracture.

\section{Augmented wagner's external fixator}

We have modified the classic Wagner's external fixator (Figure 1) to include 4 instead 2 clamps, a quarter of Ilizarov ring with Rancho cubes and if required, Aesculap clamp instead of Wagners clamp to make the fixator mechanically stable and rigid besides being versatile and patient friendly. We called this unique fixator as Augmented Wagner's External Fixator (Figure 2). Body of the fixator consists of two square telescoping rods to facilitate compression after the fixator is applied. Stud of the body of the Wagner's external fixator clamp is $8 \mathrm{~mm}$ in diameter and $32 \mathrm{~mm}$ in length instead of $6 \mathrm{~mm}$ and $20 \mathrm{~mm}$ respectively so that an Aesculap clamp can be accommodated when required. Central threaded rod (compression, distraction rod) is of stainless steel SS 304 and is of diameter of $8 \mathrm{~mm}$ instead of $6 \mathrm{~mm}$.

\section{Post-op rehabilitation}

Immobilization is done with below knee slab. Toe touch weight bearing and progressive weight bearing will be permitted based on fracture pattern and radiological evidence of healing generally begins after 4 weeks.

\section{Follow up}

At 2, 4, 6, weeks, $3^{\text {rd }}, 6^{\text {th }} 9^{\text {th }}, 12^{\text {th }}$ month and at yearly interval. $\mathrm{X}$-rays will be done on each follow up to review for alignment of fragments, angulation, signs of fracture healing, while clinically stability of the ankle will be measured. The Olerud $\mathrm{C}$ and Molander $\mathrm{H}^{[13]}$ Ankle evaluation system will be used to assess the ankle function. Augmented Wagners Fixator was compressed at follow-ups to achieve better bone to bone contact if follow-up X-rays shows its need. When there was no pain at fracture site and clinically as well as and Radiologically the fracture was healed then the fixator was removed in OPD.

\section{Results}

The mean age of the patient was 46.5 years. The Olerud $\mathrm{C}$ and Molander $\mathrm{H}$ ankle score (Figure 3) was excellent in $44.73 \%$ $(\mathrm{n}=17)$, good in $31.57 \%(\mathrm{n}=12)$, fair in $15.78 \%(\mathrm{n}=6)$ and poor in $7.89 \%(n=3)$. The ankle range of movement was near normal in $94.73 \%$ cases except in 2 patients where stiffness was encountered. The mean duration of follow up was 7 months (range 5 to 11 months). The fracture pattern were equally encountered in study and was treated and most common fixators used were simple Aesculap $42.10 \%(n=16)$ and Hybrid Aesculap $31.57 \%(\mathrm{n}=12)$. The average duration of union was 6 months and $89 \%(n=34)$ of fractures united within 7 months. $\mathrm{P}$ value $<0.05(0.066)$ was not considered significant. In few cases $n=8(21.05 \%)$ bone graft was used to 
fill the gap at fracture site as in these cases fracture was compound / comminuted or was with bone loss.

\section{Discussion}

4.1 Types of injury: In our study, we had 25(65.78\%) closed fractures and 13 compound fractures. In closed fracture, 18 patients had Tscherne type 2 injury and remaining seven has type 3 . Of the compound fractures $5(13.15 \%)$ were Grade I, $3(7.89 \%)$ of Grade II and $5(13.15 \%)$ of Grade III compound fracture tibia.

4.2 Types of fixator: We used four techniques for fixation of lower third tibia fractures as per requirement to maintain reduction. Simple Aesculap fixator (Figure 4) was used in $16(42.10 \%)$ patients. Augmented Wagner fixator was used in $7(18.42 \%)$ patients, Hybrid Aesculap fixator was used in 12 (31.57\%) patients and Hybrid wagner fixator was used in 3 (7.89\%) patients. Hybrid External Fixator is done where the fracture fragments were not in contact with each other. Screws were introduced percutaneously to bring fragment close to each other for obtaining good reduction and alignment of the fracture. Augmented Wagner's External Fixator was used in pilon fracture with metaphysealdiaphyseal comminuted fracture, where compression of fracture is contemplated post operatively to bring bone to bone contact. So Augmented Wagner's External fixator was used in presence of comminuted metaphyseal fracture, as one may need to compress fracture post operatively to bring about bone to bone contact.

4.3 Success rate: In our study with various External Fixators in 38 distal tibial Fractures, The Olerud $\mathrm{C}$ and Molander $\mathrm{H}$ ankle score was excellent in $44.73 \%(n=17)$, good in $31.57 \%$ $(n=12)$, fair in $15.78 \% \quad(n=6)$ and poor in $7.89 \% \quad(n=3)$. Vidyadhara $S$ and Rao $S^{[14]}$ et al. studied 21 patients with Ilizarov external fixator for distal tibial fracture. 11 patients $(52.38 \%)$ had excellent functional result, 5 with good, 4 had fair and 1 patient had poor result.

Vijay C et al. ${ }^{[15]}$ studied the efficacy of LRS external fixation in 45 patients in achieving anatomical reduction, stable fixation, early return to function, results with respect to bony union, soft tissue coverage and with special consideration of knee and ankle movements, limb shortening and disadvantages. While good to excellent results were seen in 28 cases amounting to $72 \%$, moderate and poor results were observed in $18 \%$ and $10 \%$ of the cases respectively.

Galante ${ }^{[3]}$ et al. studied 162 patients in 2016 using XCaliber hybrid external fixator for tibial pilon fractures. The overall functional scores were 91 (excellent) for AO/OTA type A fractures, 89 (good) for type B fractures, and 75 (satisfactory) for type $\mathrm{C}$ fractures. Ramlee ${ }^{[16]}$ et al. concluded that Deltaframe provides better stability as compared to Mitkovic and Unilateral external fixators.

4.4 Union rate: Though our union rate was $100 \%$, Orthofix fixator has an advantage of being able to be change to dynamic mode after initial callus formation. The same can be achieved with the help of Augmented Wagner External Fixator. The union rate in Vijay C et al. ${ }^{[17]}$ series is $90 \%$. Union rate of Galante et al. is 98.14 in 162 patient study.

4.5 Ankle range of motion: The ankle range of movement was near normal except in $2(5.26 \%)$ patients where stiffness was encountered. Queitsch C et al. (2006) ${ }^{[17]}$ studied 42 patients and observed that 17 patients showed no deficit in the range of movement of the ankle joint compared to their opposite side, 21 patients had a deficit of movement of $1 / 3$ and 4 patients suffered from a deficit of $2 / 3$ as compared to the opposite side.

4.6 Duration of fixator: In $89 \%$ patients radiological as well as clinical union was observed within 7 months of time. The mean union time was about 24 weeks. In $89 \%$ cases the fixator has been removed after 7 months. 34 (89\%) patients fixator were for period of 7 months. In study by Galante et al. [3], the fixators were removed after Radiographic fracture healing occurred in 95 to 143 days (average, 125 days). According to study of Vidyadhara S and Rao S (2006) ${ }^{[14]}$ the fixator was removed at an average of $26.6 \pm 4.2$ weeks (range 20-34 weeks).

4.7 complications: In our series, the complication rate was low: 2 patients of ankle stiffness $(5.26 \%), 1$ of delayed union $(2.63 \%)$ and four pin-track infections $(10.52 \%)$, resolved with oral antibiotics. In series of 162 patients of Galante et al. ${ }^{[3]}$, they had non-union (1.8\%), delayed union (1.8\%), superficial venous thrombosis $(1.2 \%)$ and fixator mobilization $(0.6 \%)$ and Forty-four pin-track infections $(26.8 \%)$. Ramos $\mathrm{T}$ et al. ${ }^{[18]}$ noticed pin tract infection in $27(69.23 \%)$ of cases which were treated either by oral antibiotics or removal of the isolated pin.

Limitations in our study include small sample size, retrospective and non-randomized study design.

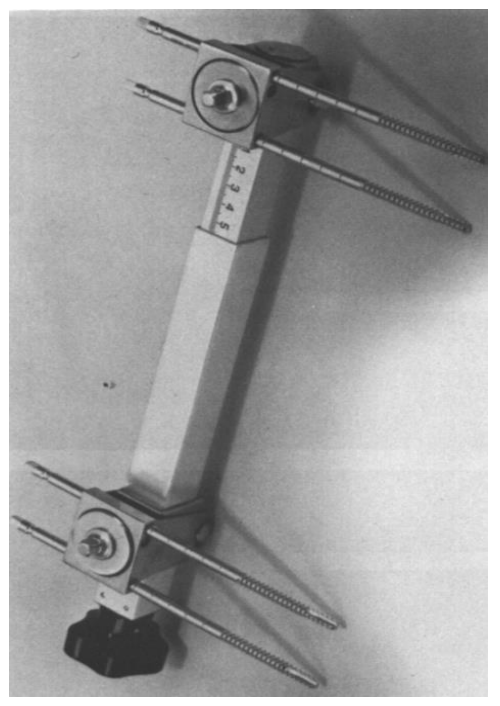

Fig 1: Classic wagner's external fixator

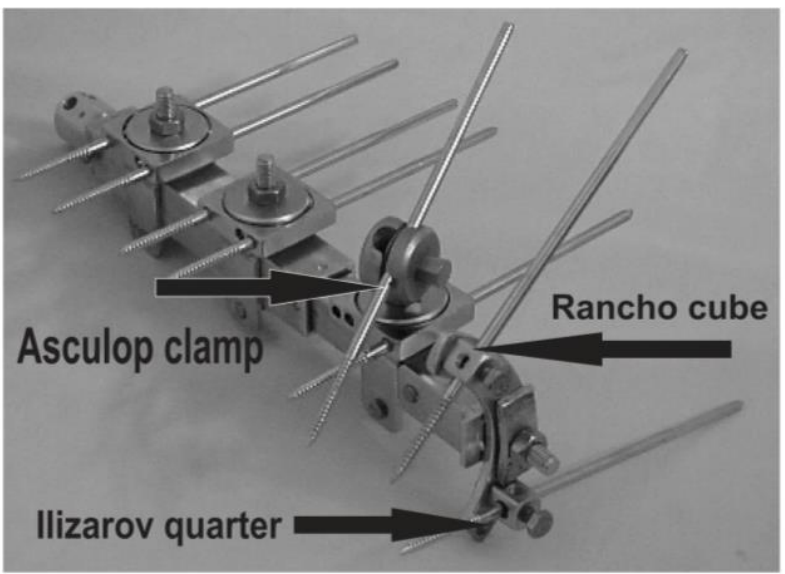

Fig 2: Augmented wagner's external fixator 


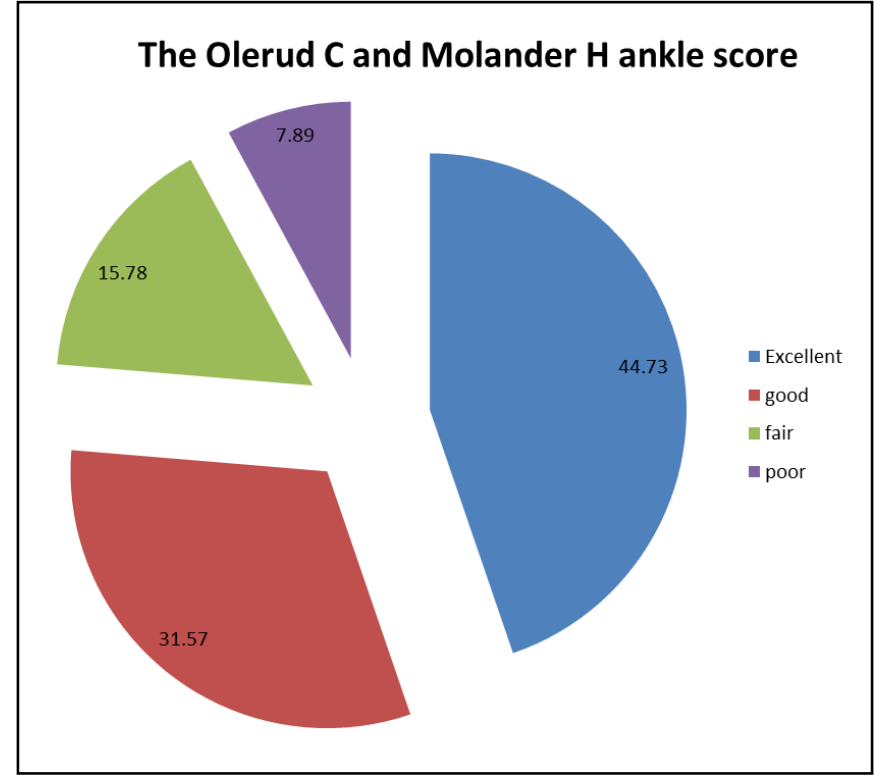

Fig 3: The Olerud $\mathrm{C}$ and Molander $\mathrm{H}$ ankle score

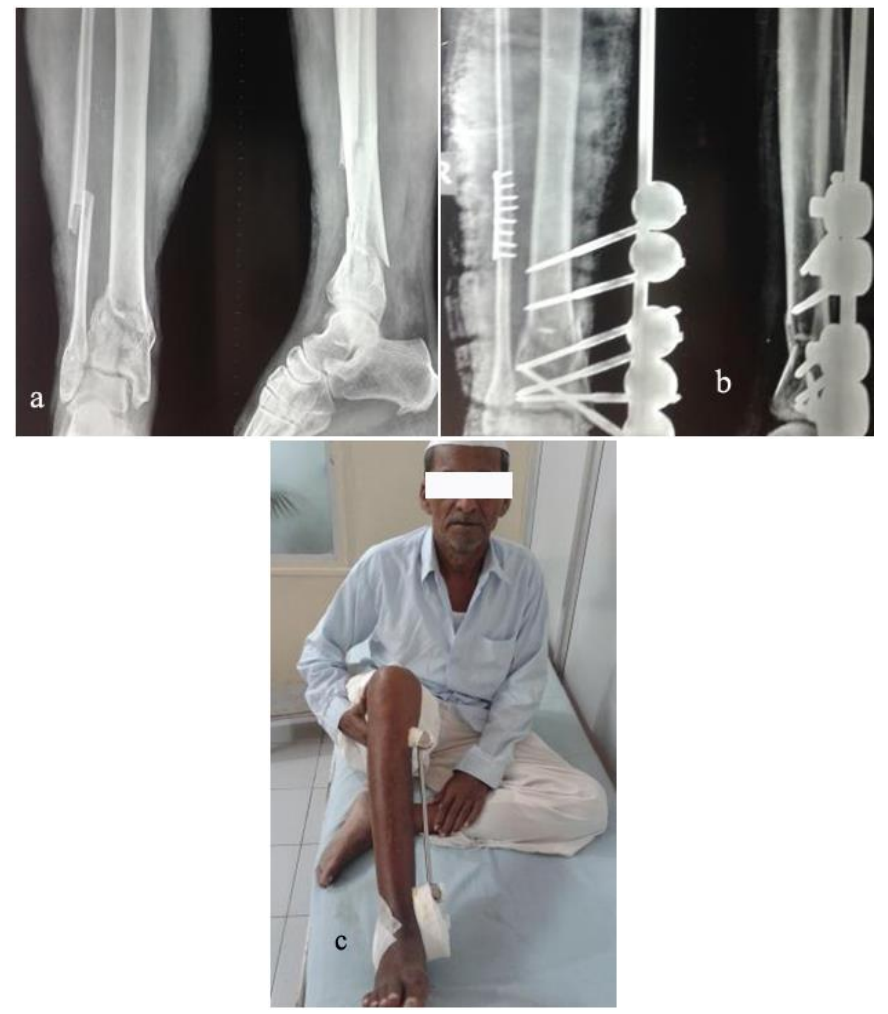

Fig 4: 52 Year old male with type 43-C2 compound grade 2 fracture treated with simple Aesculap fixator a-pre-op x-ray b- post op x-ray. c- patient with simple Aesculap fixator

\section{Conclusion}

External Fixators with or without limited percutaneous internal fixation is a reliable method for stabilization of high energy (Tscherne 2 and 3, compound) lower third tibial fractures. It's a good alternative to other methods of fixation in lower third tibia fracture.

\section{References}

1. Kellam JF, Waddell JP. Fractures of the distal tibial metaphysis with intra-articular extension-the distal tibial explosion fracture. J Trauma. 1979; 19(8):593-601

2. Scaglione M, Celli F, Casella F, Fabbri L. Tibial pilon fractures treated with hybrid external fixator: analysis of 75 cases. Musculoskelet Surg. 2018, 5. Doi: 10.1007/s12306-018-0550-z.

3. Galante $\mathrm{N}$, et al. Hybrid external fixation in the treatment of tibial pilon fractures: A retrospective analysis of 162 fractures. Injury. 47 Suppl 4. 10.1016/j.injury. 2016.07.045.

4. Korkmaz A, Ciftdemir M, Ozcan M, Copurog lu C, Sarıdog an K. The analysis of the variables, affecting outcome in surgically treated tibia pilon fractured patients. Injury. 2013; 44(10):1270-4.

5. Haidukewych GJ. Temporary external fixation for the management of complex intra- and periarticular fractures of the lower extremity. J Orthop Trauma 2002; 16(9):678-85.

6. Lavini F, et al. Temporary bridging external fixation in distal tibial fracture. Injury. 45. 10.1016/j.injury.2014.10.025.

7. Rudloff MI. Fractures of the lower extremity. In: Canale ST, Beaty JH. Campbell's Operative Orthopaedics. 12th Edition. Vol.3. Canada: Elsevier Mosby, 2012, 2632.

8. Joveniaux P, Ohl X, Harisboure A, Berrichi A, Labatut L, Simon $\mathrm{P}$ et al.. Distal tibia fractures: management and complications of 101 cases. Int Orthop. 2010; 34(4):583588

9. Pollak AN, McCarthy ML, Bess RS, Agel J, Swiontkowski MF. Outcomes after treatment of highenergy tibial plafond fractures. J Bone Joint Surg Am. 2003; 85-A(10):1893-900.

10. Fracture and dislocation compendium. Orthopaedic Trauma Association Committee for Coding and Classification. J Orthop Trauma. 1996; 10(1:v-ix), 1-154.

11. Tscherne H. Pathophysiology and classification of soft tissue injuries associated with fractures. In: Tscherne $\mathrm{H}$, Gotzen L, editors. Fractures with soft tissue injuries [German]. Berlin: Springer-Verlag, 1984, 6-7.

12. Gustilo RB, Anderson JT. Prevention of infection in the treatment of one thousand and twenty-five open fractures of long bones: retrospective and prospective analyses. J Bone Joint Surg Am. 1976; 58:453-8.

13. Olerud C, Molander H. A scoring scale for symptom evaluation after ankle fracture. Archieves of Orthopaedics and Traumatic Surgery.1984; 103(3):190-4.

14. Vidyadhara S, Rao S Ilizarov. Treatment of complex tibial pilon fractures. Int Orthop. 2006; 30(2):113-117.

15. Vijay C, Mahenra Kumar KL, Manjappa CN. Management of Open Type IIIA and Type IIIB Fractures Tibia With LRS External Fixator. The Internet Journal of Orthopedic Surgery. 2010; 18(2).

16. Ramlee MH, Kadir MR, Murali MR, Kamarul T. Finite element analysis of three commonly used external fixation devices for treating Type III pilon fractures. Med Eng Phys. 2014; 36(10):1322-30.

17. Queitsch C, Kienast B, Fuchs S, Seide K. Fracture of the distal lower limb: two-stage surgical treatment with external fixator and locked-screw plate. Zentralbl Chir. German. 2006; 131(3):194-9.

18. Ramos T, Karlsson J, Eriksson BI, Nistor L. Treatment of distal tibial fractures with the Ilizarov external fixator - a prospective observational study in 39 consecutive patients. BMC Musculoskeletal Disorders. 2013; 14:30. 